\title{
Ganglioside Synthase Knockout Reduces Prion Disease Incubation Time in Mouse Models
}

Atsushi Kobayashi, * Zechen Qi, * Taishi Shimazaki, ${ }^{*}$ Yoshiko Munesue, ${ }^{*}$ Tomomi Miyamoto, ${ }^{\dagger}$ Norikazu Isoda, ${ }^{\ddagger}$ Hirofumi Sawa, ${ }^{\ddagger \mathbb{T}}$ Keisuke Aoshima, ${ }^{*}$ Takashi Kimura, ${ }^{*}$ Shirou Mohri, "Tetsuyuki Kitamoto," Tadashi Yamashita, ** and Ichiro Miyoshi ${ }^{\dagger \dagger}$

\begin{abstract}
From the Laboratory of Comparative Pathology, * Faculty of Veterinary Medicine, the Global Station for Zoonosis Control, ${ }^{\ddagger}$ Global Institute for Collaborative Research and Education, the Unit of Risk Analysis and Management ${ }^{\S}$ and the Division of Molecular Pathobiology, "Research Center for Zoonosis Control, Hokkaido University, Sapporo; the Center for Experimental Animal Science, ${ }^{\dagger}$ Graduate School of Medical Sciences, Nagoya City University, Nagoya; the Departments of Neurological Science $\|$ and Laboratory Animal Medicine ${ }^{\dagger \dagger}$ Tohoku University Graduate School of Medicine, Sendai; and the Laboratory of Biochemistry, ** Graduate School of Veterinary Medicine, Azabu University, Sagamihara, Japan
\end{abstract}

\author{
Accepted for publication \\ November 16, 2018. \\ Address correspondence to \\ Atsushi Kobayashi, Ph.D., \\ D.V.M., Laboratory of \\ Comparative Pathology, Fac- \\ ulty of Veterinary Medicine, \\ Hokkaido University, Kita 18 \\ Nishi 9, Kita-ku, Sapporo \\ 060-0818, Japan. E-mail: \\ kobayashi@vetmed.hokudai.ac. \\ jp.
}

\begin{abstract}
Localization of the abnormal and normal isoforms of prion proteins to detergent-resistant membrane microdomains, lipid rafts, is important for the conformational conversion. Lipid rafts are enriched in sialic acid-containing glycosphingolipids (namely, gangliosides). Alteration in the ganglioside composition of lipid rafts can affect the localization of lipid raft-associated proteins. To investigate the role of gangliosides in the pathogenesis of prion diseases, we performed intracerebral transmission study of a scrapie prion strain Chandler and a Gerstmann-Sträussler-Scheinker syndrome prion strain Fukuoka-1 using various knockout mouse strains ablated with ganglioside synthase gene (ie, GD2/GM2 synthase, GD3 synthase, or GM3 synthase). After challenge with the Chandler strain, GD2/GM2 synthase knockout mice showed $20 \%$ reduction of incubation time, reduced prion protein deposition in the brain with attenuated glial reactions, and reduced localization of prion proteins to lipid rafts. These results raise the possibility that the gangliosides may have an important role in prion disease pathogenesis by affecting the localization of prion proteins to lipid rafts. (Am J Pathol 2019, 189: 677-686; https:// doi.org/10.1016/j.ajpath.2018.11.009)
\end{abstract}

Prion diseases are fatal transmissible neurodegenerative diseases, including Creutzfeldt-Jakob disease, GerstmannSträussler-Scheinker syndrome, and fatal familial insomnia in humans, or bovine spongiform encephalopathy, chronic wasting disease, and scrapie in animals. Accumulation of an abnormal protease-resistant isoform of prion protein $\left(\mathrm{PrP}^{\mathrm{Sc}}\right)$, which is generated by conformational conversion of the normal cellular isoform $\left(\operatorname{PrP}^{\mathrm{C}}\right)$, is one of the pathognomonic features of prion diseases. ${ }^{1}$

Membrane microdomains where $\mathrm{PrP}^{\mathrm{C}}$ and $\mathrm{PrP}^{\mathrm{Sc}}$ are localized are lipid rafts. ${ }^{2-6}$ Lipid rafts are enriched in cholesterol, sphingolipids, and glycosylphosphatidylinositol (GPI)-anchored proteins, including PrP, and show partial resistance against mild detergent treatment. ${ }^{7,8}$ Therefore, lipid rafts buoy toward low-density fractions in density gradient ultracentrifugation after mild detergent treatment (namely, flotation assay). Lipid rafts have been reported to serve many microorganisms for infection or serve the clustering of receptors or signaling molecules to facilitate signal transduction. ${ }^{8,9}$ In prion disease pathogenesis, the localization of $\operatorname{PrP}^{\mathrm{C}}$ and $\mathrm{PrP}^{\mathrm{Sc}}$ to lipid rafts has been reported to be important for the conformational conversion. ${ }^{3}$

Gangliosides are sialic acid-containing glycosphingolipids highly expressed in the brain. Gangliosides are synthesized in the Golgi apparatus by specific glycosyltransferases, the expression of which controls the steadystate levels of gangliosides. ${ }^{10}$ Gangliosides are characterized by the number and positions of sialic acids that define their

Supported by Japan Society for the Promotion of Science grant-in-aid for scientific research 18K05963 (A.K.), The Ichiro Kanehara Foundation (A.K.), the Suhara Memorial Foundation (A.K.), and the Kato Memorial Trust for Nambyo Research (A.K.).

Disclosures: None declared. 
classification into $\mathrm{A}, \mathrm{M}, \mathrm{D}, \mathrm{T}, \mathrm{Q}$, and $\mathrm{P}$ (zero to five sialic acids) and a, b, and c series (one, two, or three sialic acids on internal galactose residue) (Figure 1). Gangliosides are embedded in the outer layer of the plasma membrane and are one of major components of lipid rafts. ${ }^{7}$ Therefore, alteration in the ganglioside composition of lipid rafts can affect the localization of lipid raft-associated proteins. ${ }^{11-13}$ For example, knockout (KO) mice lacking GD2/GM2 synthase, in which GA2, GM2, GD2, GT2, and downstream gangliosides are depleted, show the dispersion of lipid raft-associated proteins, such as caveolin 1 or flotillin 1 , from lipid raft fractions in flotation assay. ${ }^{13}$ Furthermore, in KO mice lacking both GD2/GM2 synthase and GD3 synthase, a GPI-anchored complement-regulatory protein CD55/decay-accelerating factor also disperses from lipid rafts, and unfavorable activation of complement system occurs. ${ }^{12}$ Complement activation starts with the activation of $\mathrm{C} 1 \mathrm{q}$ by antigen-antibody complex or spontaneous hydrolysis of $\mathrm{C} 3$ and causes a cascade of further cleavage and activation processes of complement proteins. Complement activation results in the accumulation of complement proteins, such as $\mathrm{Clq}$ or $\mathrm{C} 3 \mathrm{~b}$, and the formation of the membrane attack complex. In the KO mice lacking both GD2/ GM2 synthase and GD3 synthase, gene expression of complement proteins, such as $\mathrm{C} 1 \mathrm{qa}, \mathrm{C} 3$, or $\mathrm{C} 4$, was upregulated, and deposition of $\mathrm{Clq}$ in the brain increased. ${ }^{12,13}$ Meanwhile, an activation of the complement system and accumulation of C1q, C3, or membrane attack complex have also been demonstrated in brains of human patients with prion diseases or prion-infected animals. ${ }^{14,15}$ The role of complement activation in prion disease pathogenesis has been proposed to cause degeneration of prion-infected neurons or to facilitate microglial phagocytosis of prion-infected neurons. ${ }^{15}$

In this study, we performed a prion transmission study using various ganglioside synthase knockout mouse strains to investigate the role of gangliosides in the pathogenesis of prion diseases.

\section{Materials and Methods}

\section{Ethics Statement}

Animal experiments were performed in strict accordance with the Regulations for Animal Experiments and Related Activities at Hokkaido University and Fundamental Guidelines for Proper Conduct of Animal Experiment and Related Activities in Academic Research Institutions by Ministry of Education, Culture, Sports, Science and Technology in Japan (notice number 71). The protocol was approved by the Institutional Animal Care and Use Committees of Hokkaido University (14-0170).

Mice

Generation of KO mice lacking GD2/GM2 synthase (B4GALNT1), GD3 synthase (ST8SIA1), or GM3 synthase (ST3GAL5) has been reported previously. ${ }^{16,17}$ These mice were backcrossed to C57BL/6, and the resulting heterozygous animals were intercrossed to provide homozygous $\mathrm{KO}$ mice and wild-type (WT) littermate controls. Thus, all of the KO mice and WT littermate controls were on a C57BL/6 background.

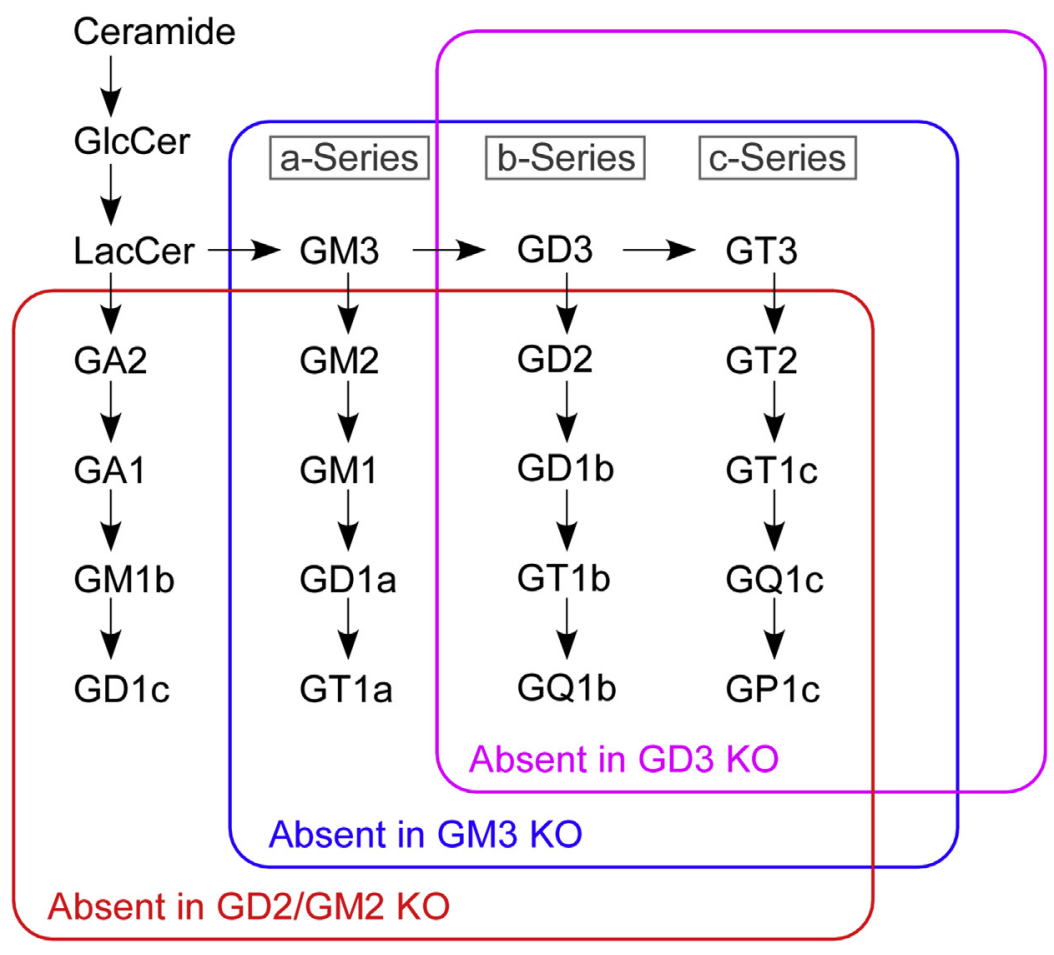

Figure 1 Biosynthetic pathway of gangliosides and elimination of particular gangliosides in $\mathrm{KO}$ mouse strains. GD2/GM2, GM3, and GD3 K0 mice lack gangliosides, indicated by red, blue, and pink lines, respectively. 


\section{Sources of Inocula}

A mouse-adapted scrapie prion strain Chandler ${ }^{18}$ was kindly provided by Dr. Motohiro Horiuchi (Faculty of Veterinary Medicine, Hokkaido University, Sapporo, Japan). A mouseadapted Gerstmann-Sträussler-Scheinker syndrome prion strain Fukuoka- $1^{19}$ was maintained in C57BL/6 mice. The inocula were prepared from the brain of terminally ill mice.

\section{Transmission Experiments}

Intracerebral inoculation was performed as described. ${ }^{20}$ Briefly, $10 \%$ brain homogenates were prepared in sterile phosphate-buffered saline using glass homogenizers, and 20 $\mu \mathrm{L}$ of the homogenates was intracerebrally inoculated into mice $(n=6$ or 7$)$. The inoculated mice were sacrificed at a predefined clinical end point or at the time point showing intercurrent illness. One hemisphere of the brain was fixed in $10 \%$ buffered formalin for histopathological analysis, and the other hemisphere was immediately frozen for biochemical analysis.

\section{Immunohistochemistry}

Formalin-fixed mouse brain tissues were treated with $60 \%$ formic acid for 1 hour to inactivate the infectivity and embedded in paraffin. The embedded tissues were divided into sections $(5 \mu \mathrm{m}$ thick). Tissue sections were pretreated by hydrolytic autoclaving before PrP immunohistochemistry. ${ }^{21}$ The anti-PrP antiserum PrP-N, ${ }^{22}$ rabbit anti-ionized calcium-binding adapter molecule 1 (Iba1) polyclonal antibody (FUJIFILM Wako Pure Chemical Corp., Osaka, Japan), and rabbit anti-glial fibrillary acidic protein (GFAP) polyclonal antibody (Dako, Glostrup, Denmark) were used as the primary antibodies. Goat-anti-rabbit Ig polyclonal antibody labeled with the peroxidase-conjugated dextran polymer, EnVision ${ }^{+}$(Dako), was used as the secondary antibody. For routine histopathological analysis, the tissue sections were also stained with hematoxylin and eosin.

\section{PrPSc Purification}

$\operatorname{PrP}^{\mathrm{Sc}}$ was purified from the mouse brain as described. ${ }^{23}$ Briefly, brain tissues were homogenized in $2 \mathrm{~mL}$ of lysis buffer $[100 \mathrm{mmol} / \mathrm{L}$ tris-HCl, $\mathrm{pH} 8.0,10 \mathrm{mmol} / \mathrm{L} \mathrm{NaCl}, 10$ $\mathrm{mmol} / \mathrm{L} \mathrm{MgCl}_{2}, 2 \%$ Triton X-100, and $25 \mathrm{U} / \mathrm{mL}$ DNase I (Takara Bio, Shiga, Japan)] and digested with collagenase (1 mg/200 mg tissue) (FUJIFILM Wako Pure Chemical Corp.) overnight at room temperature. Collagenase digestion disrupts the connective tissue and improves the accessibility of detergents and/or proteinase $\mathrm{K}(\mathrm{PK})$ to $\mathrm{PrP}^{\mathrm{Sc}}{ }^{24}$ The digested homogenates were ultracentrifuged at $453,000 \times g$ for 30 minutes at $4^{\circ} \mathrm{C}$, and the pellets were resuspended and sonicated in $870 \mu \mathrm{L}$ of PK-digestion buffer [100 mmol/L tris-HCl, pH 8.0, and 5\% Sarkosyl (Sigma-
Aldrich, St. Louis, MO)]. The resuspended samples were centrifuged at $10,000 \times g$ for 3 minutes to remove the cell debris, and the supernatants $(800 \mu \mathrm{L})$ were digested with PK (4 $\mu \mathrm{g} / 200 \mathrm{mg}$ tissue) (FUJIFILM Wako Pure Chemical Corp.) for 1 hour at $37^{\circ} \mathrm{C}$. It has been reported that these conditions for PK digestion were sufficient for the complete digestion of normal $\mathrm{PrP}^{\mathrm{C}}$ and that higher PK concentrations caused unfavorable degradation of $\operatorname{PrP}^{\mathrm{Sc}} \cdot{ }^{25}$ The PK-digested proteins were precipitated by adding $200 \mu \mathrm{L}$ of $99.5 \%$ ethanol and ultracentrifugation at $135,000 \times g$ for $30 \mathrm{mi}-$ nutes at $4^{\circ} \mathrm{C}$. The pellets were resuspended in $400 \mu \mathrm{L} / 200$ $\mathrm{mg}$ tissue of Laemmli's sample buffer $(60 \mathrm{mmol} / \mathrm{L}$ tris- $\mathrm{HCl}$, $\mathrm{pH} 6.8,5 \%$ glycerol, $2 \%$ SDS, and $0.01 \%$ bromophenol
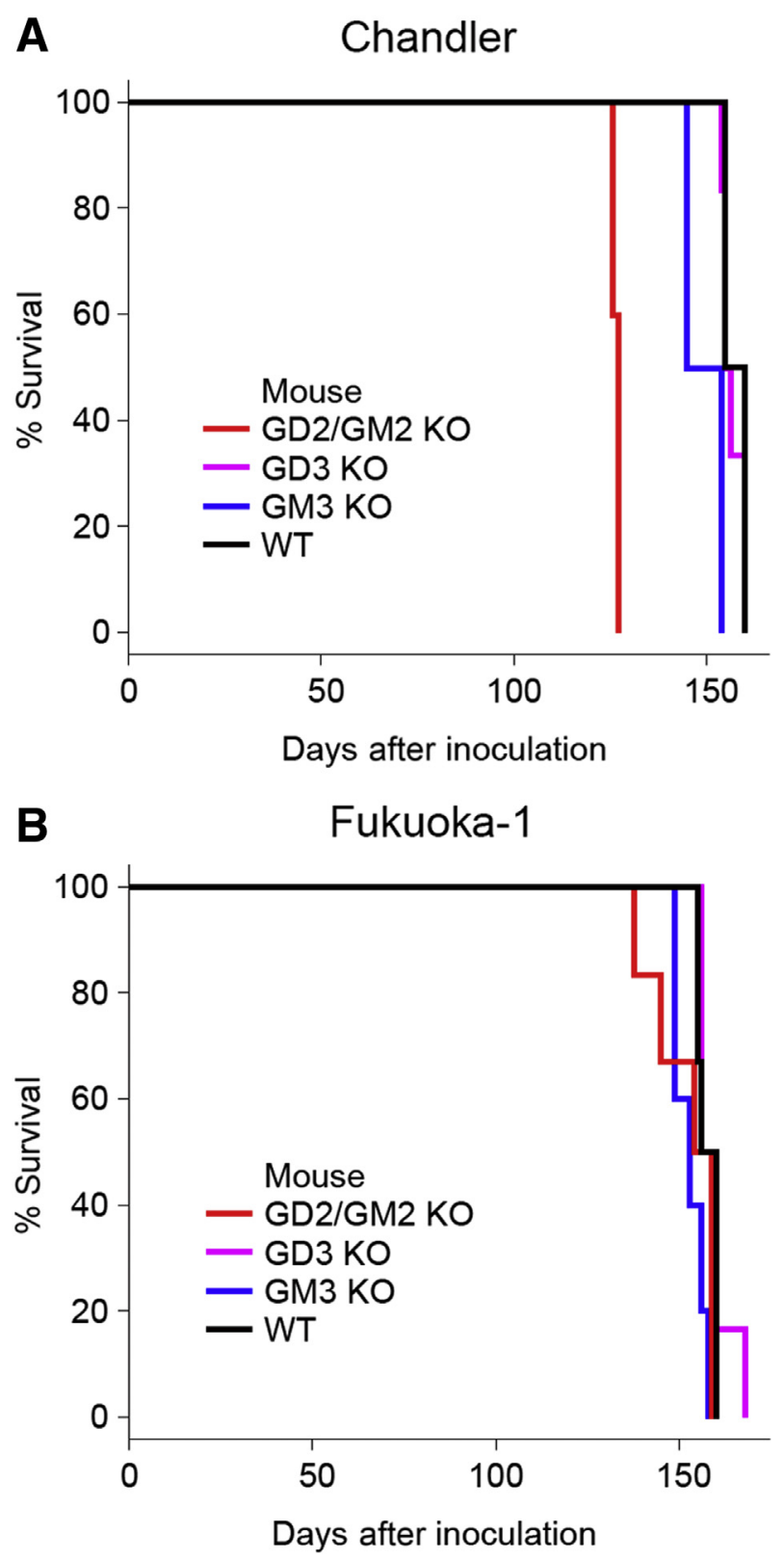

Figure 2 Kaplan-Meier survival curves. Intracerebral transmission of Chandler (A) or Fukuoka-1 (B) strain to each KO mouse strain or wild-type (WT) littermate controls, respectively. 
A

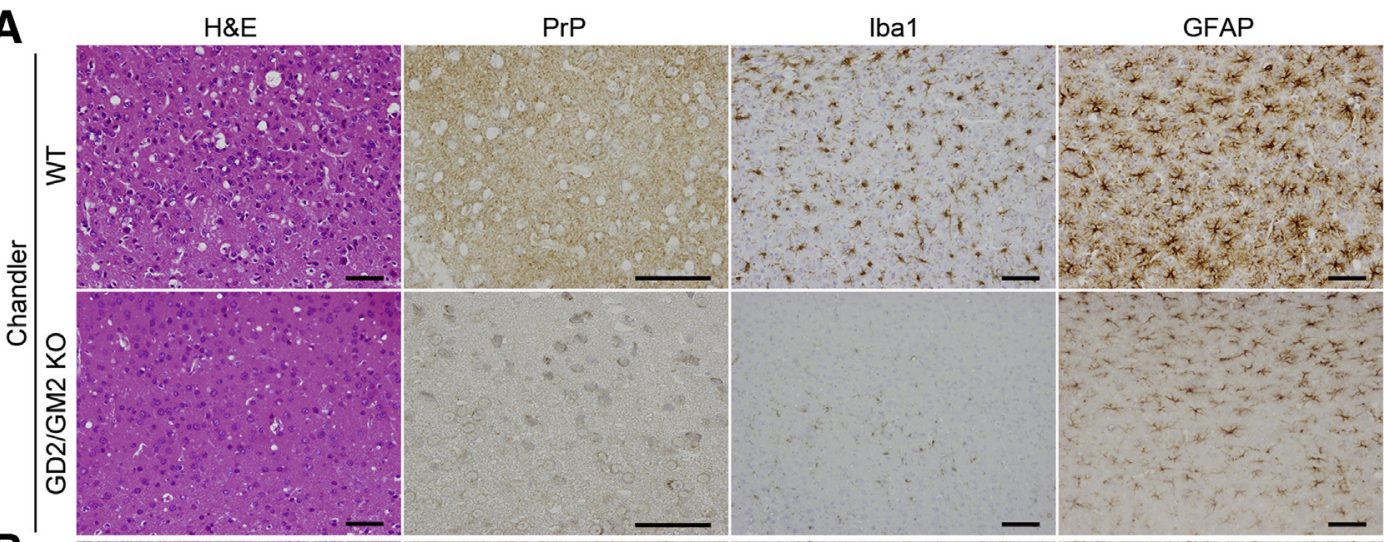

B

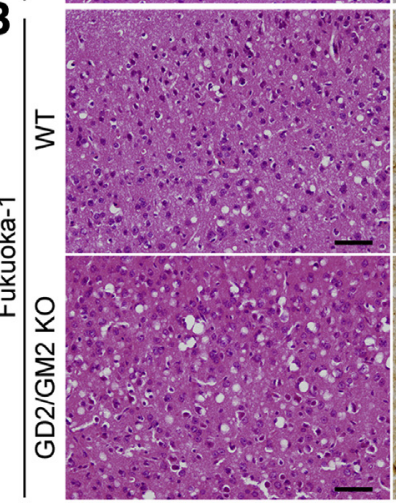

C
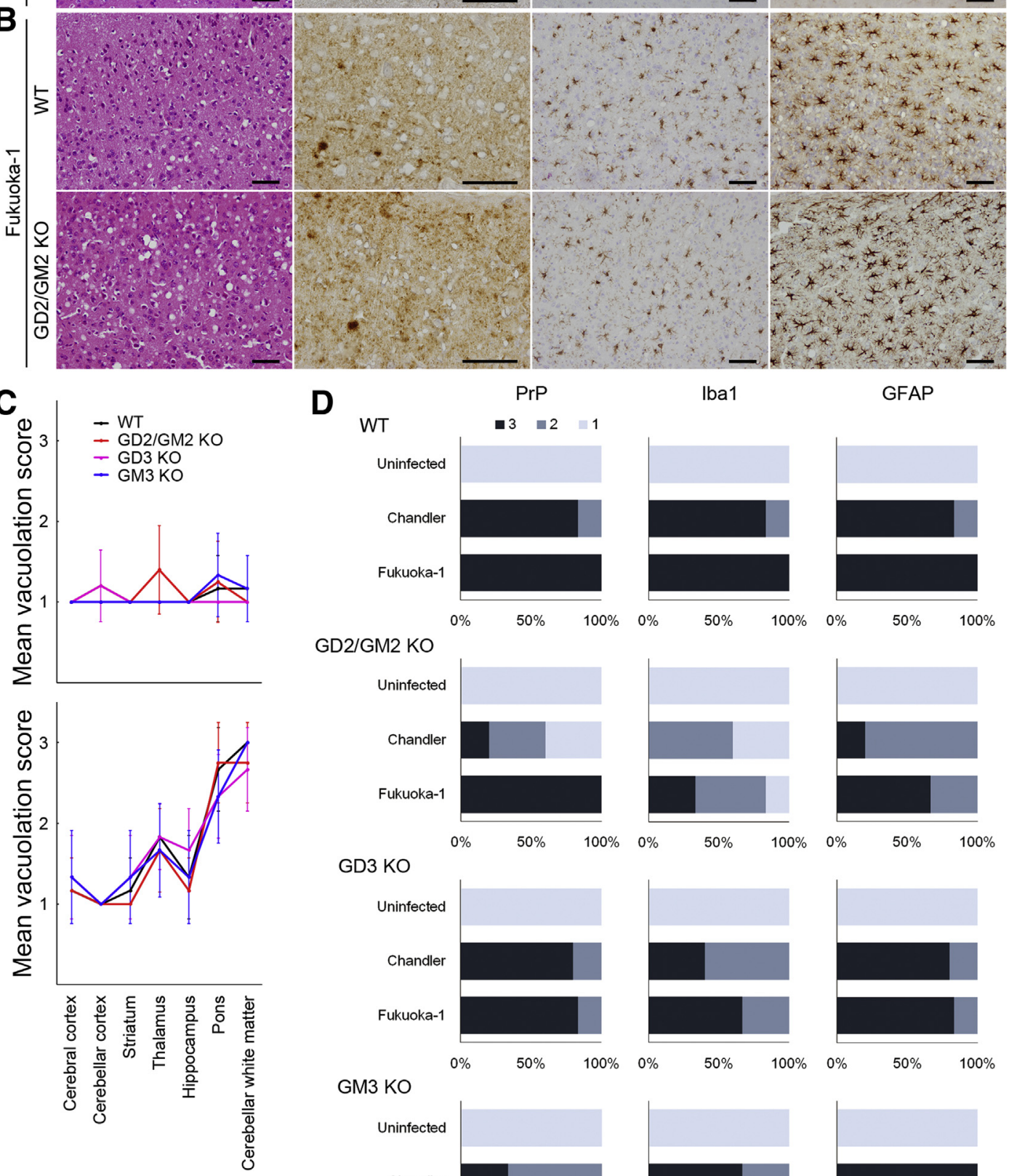

D

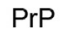

lba1

GFAP
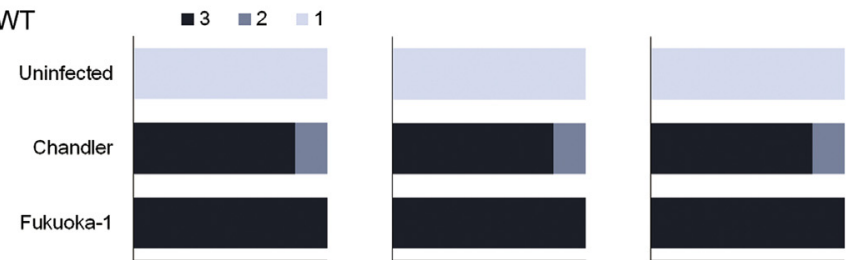

GD2/GM2 KO
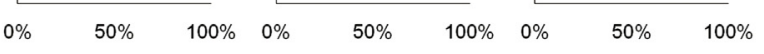

GD2/GM2 KO
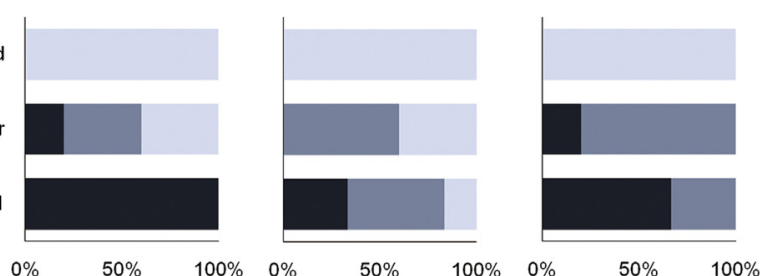

GD3 KO
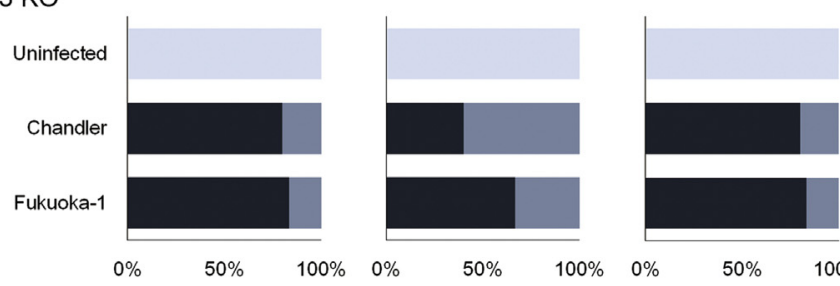

GM3 KO
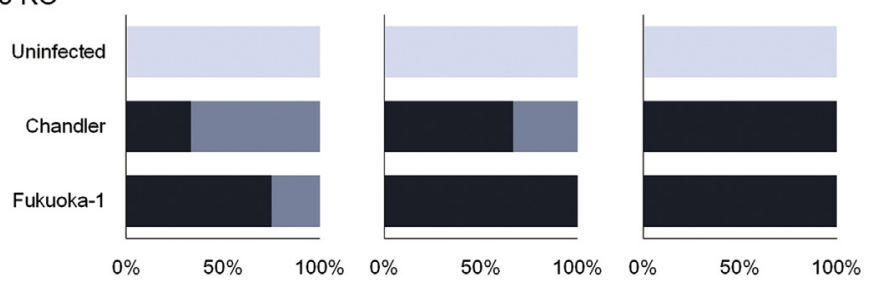
blue) and boiled at $100^{\circ} \mathrm{C}$ for 5 minutes. To examine the expression level of $\mathrm{PrP}^{\mathrm{C}}, \mathrm{C} 1 \mathrm{qa}$, and $\beta$-actin, $10 \%$ homogenates were prepared from uninfected mouse brains using the lysis buffer. The homogenates were boiled with the addition of $0.25 \times$ volume of $5 \times$ Laemmli's sample buffer.

\section{Flotation Assay}

To isolate lipid rafts, a flotation assay was performed as described previously. ${ }^{26}$ Briefly, $10 \%$ homogenates were prepared from uninfected mouse brains using citrate buffer ( $20 \mathrm{mmol} / \mathrm{L}$ sodium citrate and $137 \mathrm{mmol} / \mathrm{L} \mathrm{NaCl}, \mathrm{pH} \mathrm{6.0)}$. The homogenates were centrifuged at $1000 \times g$ for 5 minutes at $4^{\circ} \mathrm{C}$ to remove cell debris and nuclei. The supernatants were mixed with $1 \times$ volume of ice-cold Brij O-10 extraction buffer $[0.1 \%$ Brij O-10 (Sigma-Aldrich), 20 $\mathrm{mmol} / \mathrm{L}$ sodium citrate, and $137 \mathrm{mmol} / \mathrm{L} \mathrm{NaCl}, \mathrm{pH} \mathrm{6.0)}$ and incubated on a rocker at $4{ }^{\circ} \mathrm{C}$ for 30 minutes, and then mixed with $1.4 \times$ volume of $60 \%$ Optiprep (Axis-Shield, Dundee, UK). In $12 \mathrm{~mL}$ polycarbonate centrifuge tubes (Beckman Coulter, Brea, CA), $9 \mathrm{~mL}$ of $0 \%$ to $30 \%$ Optiprep continuous gradients were prepared by Gradient Master (BioComp Instruments, Fredericton, NB, Canada), according to the manufacturer's instruction, and underlaid with $2 \mathrm{~mL}$ of the Brij O-10 extracted samples. The gradients were centrifuged in a prechilled Beckman SW41 rotor (Beckman Coulter) at $40,000 \times g$ for 130 minutes at $4^{\circ} \mathrm{C}$. The samples were split to 18 fractions $(600 \mu \mathrm{L}$ each) from top (fraction 1$)$ to bottom (fraction 18) and boiled with the addition of $150 \mu \mathrm{L}$ of $5 \times$ Laemmli's sample buffer.

\section{Western Blot Analysis}

Protein samples were subjected to SDS-PAGE using $13.5 \%$ tris-glycine long gels of $15 \mathrm{~cm}$ length and Western blot analysis, as described. ${ }^{27}$ The anti-PrP monoclonal antibody SAF83 (Bertin Bioreagents, Montigny le Bretonneux, France), anti- $\beta$-actin monoclonal antibody $2 \mathrm{~F} 3$ (FUJIFILM Wako Pure Chemical Corp.), anti-flotillin 1 monoclonal antibody 18/Flotillin-1 (BD Biosciences, San Jose, CA), antiC1qa polyclonal antibody (Abcam, Cambridge, UK), antiCD55 monoclonal antibody number 583905 (R\&D Systems, Minneapolis, MN), anti-voltage-gated calcium channel auxiliary subunit $\alpha 2 \delta-1$ (CACNA2D1) monoclonal antibody 20A (Abcam), and anti-Thy1.2 monoclonal antibody (Bio-Rad, Hercules, CA) were used as the primary antibodies. The anti-mouse EnVision+ (Dako), anti-rabbit EnVision+ (Dako), and electrochemiluminescent anti-rat IgG antibody (GE Healthcare, Chicago, IL) were used as the secondary antibodies. The blots were visualized with Luminata Forte Western HRP substrate (MilliporeSigma, Burlington, MA), and images were obtained by imaging device ImageQuant LAS 4000 mini (GE Healthcare). The signal intensities of the Western blot analyses were quantified with ImageQuant TL software version 7.0 (GE Healthcare).

\section{Image Analysis}

Severity of spongiform change was classified into three scores: 1 , negative/mild (approximately $0 \%$ to $20 \%$ of the tissue section showed spongiform change); 2 , moderate (approximately $20 \%$ to $60 \%$ of the tissue section showed spongiform change); and 3, severe (approximately 60\% to $100 \%$ of the tissue section showed spongiform change). Immunohistochemical staining intensities were classified into three scores: 1, negative/weak (approximately 0\% to $20 \%$ of the tissue section showed immunoreactivity); 2 , moderate (approximately $20 \%$ to $60 \%$ of the tissue section showed immunoreactivity); and 3, high (approximately 60\% to 100\% of the tissue section showed immunoreactivity). Cerebral cortex, cerebellar cortex, striatum, thalamus, hippocampus, pons, and cerebellar white matter sections were used for the scoring of spongiform change, and cerebral cortex sections were used for the scoring of immunohistochemistry. Scoring was performed independently by two pathologists in a blinded manner (A.K. and Z.Q.), and the scores were finalized after discussion. Data were collected from all diseased mice and are represented as means \pm SEM in the scoring of spongiform change or as percentage of animals with each score in the scoring of immunohistochemistry.

\section{Statistical Analysis}

The Kaplan-Meier log-rank test was used to analyze survival data in transmission study. Tukey-Kramer test was used to analyze signal intensity data in Western blot analysis. The statistical tests were performed using the statistical software EZR version $1.36 .{ }^{28} P<0.05$ was considered statistically significant.

Figure 3 Neuropathological features. A: Histopathological analysis of spongiform changes in hematoxylin and eosin (H\&E)-stained sections and immunohistochemical analysis for $\mathrm{Pr}^{\mathrm{TSE}}$ deposition, ionized calcium-binding adapter molecule 1 (Iba1)-positive microglia, and glial fibrillary acidic protein (GFAP) positive astroglia in the cerebral cortices of the Chandler strain-inoculated mice. GD2/GM2 K0 mice showed less PrPTE deposition in the neuropil and attenuated microglial and astroglial reactions. Data are representative of tissue sections from six mice per group. B: Histopathological analysis of the Fukuoka-1 strain-inoculated mice. C: Regional distribution of spongiform change in the brain. Spongiform change was scored on a scale of 1 to $3: 1$, negative/mild (approximately $0 \%$ to $20 \%$ of the tissue section showed spongiform change); 2 , moderate (approximately $20 \%$ to $60 \%$ of the tissue section showed spongiform change); and 3, severe (approximately $60 \%$ to $100 \%$ of the tissue section showed spongiform change). D: Scoring of the immunohistochemical signal intensities. The signal intensities were classified into three scores: 1 , negative/weak (approximately $0 \%$ to $20 \%$ of the tissue section showed immunoreactivity); 2 , moderate (approximately $20 \%$ to $60 \%$ of the tissue section showed immunoreactivity); and 3, high (approximately $60 \%$ to $100 \%$ of the tissue section showed immunoreactivity). Data are expressed as percentage of animals with each score. The scoring was performed by two pathologists independently (A.K. and Z.Q.), on the basis of the signal intensities in the cerebral cortices. Data are expressed as means \pm SEM (C). $n=6$ or 7 (C and D). Scale bars $=50 \mu \mathrm{m}(\mathbf{A})$. WT, wild type. 

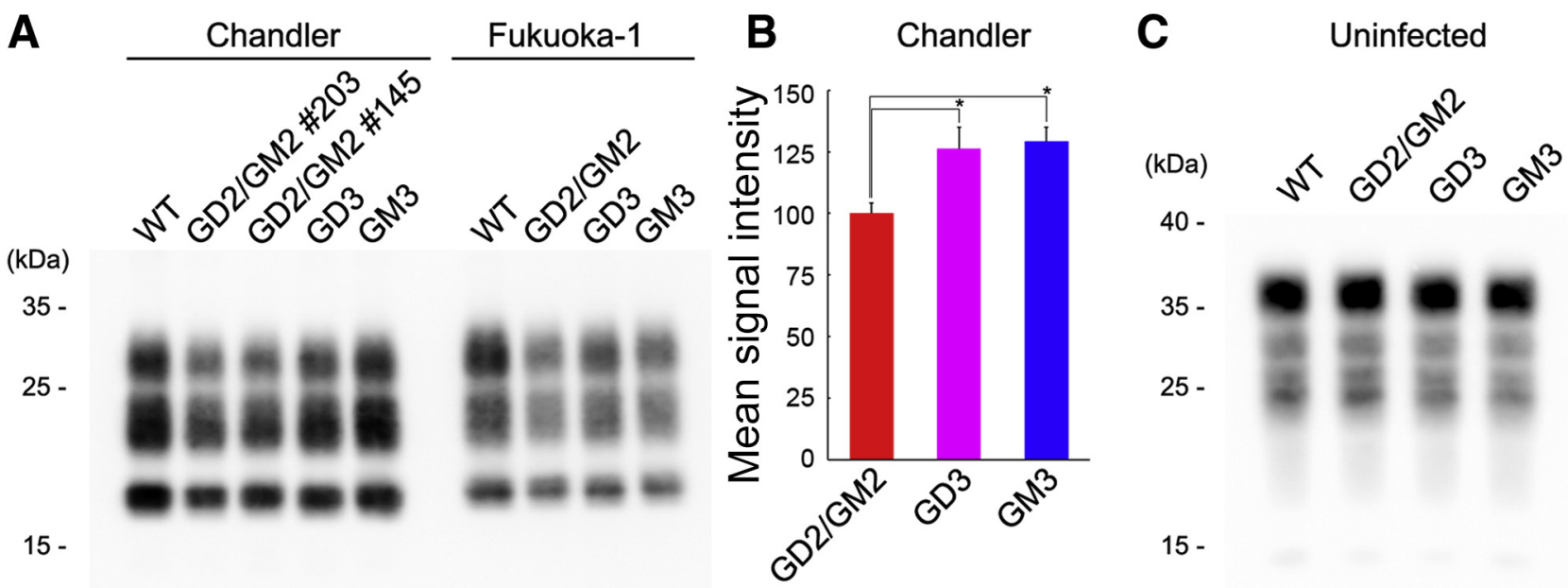

Figure 4 Western blot analysis of PrP. A: Proteinase K (PK)-resistant PrPS in the brain of Chandler- or Fukuoka-1-inoculated mice. There was no difference in the biochemical properties of PK-resistant PrP ${ }^{S c}$ among mouse strains. The Chandler-inoculated mice consistently produce lower apparent molecular mass of unglycosylated $\mathrm{PrP}^{\mathrm{Sc}}$ fragments compared with those of the Fukuoka-1-inoculated mice regardless of their genotype. The Chandlerinoculated GD2/GM2 K0 mice showed slightly decreased apparent amount of PrP ${ }^{\mathrm{Sc}}$ compared with wild-type (WT), GD3 K0, or GM3 K0 mice, irrespective of the degree of PrP ${ }^{\mathrm{TSE}}$ deposition in the immunohistochemical analysis. For example, a GD2/GM2 K0 mouse (number 145) that showed reduced PrP ${ }^{\mathrm{TSE}}$ deposition in the immunohistochemical analysis (ie, score 1) has similar apparent amount of PK-resistant PrPSc compared with that of another GD2/GM2 K0 mouse (number 203) that shows abundant PrP ${ }^{\mathrm{TSE}}$ deposition in the immunohistochemistry (ie, score 3). A brain sample, equivalent to $125 \mu \mathrm{g}$ in wet weight, was loaded in each lane. B: Quantification of the amount of PK-resistant PrP ${ }^{\mathrm{Sc}}$ in the brain of the Chandler-inoculated mice. GD2/GM2 K0 mice show reduced PrP ${ }^{S c}$ accumulation compared with GD3 K0 mice or GM3 K0 mice. The mean signal intensity of PrPS in GD2/GM2 K0 mice was assigned as 100 . Statistical significance calculated by Tukey-Kramer test. C: Expression levels of $\mathrm{PrP}^{\mathcal{C}}$ in the brain of uninfected mice. A brain sample, equivalent to $50 \mu \mathrm{g}$ in wet weight, was loaded in each lane. Data are expressed as means \pm SEM (B). $n=4$ or 5 (B). ${ }^{\star} P<0.05$.

\section{Results}

Transmission of Prions to KO Mice Lacking Ganglioside Synthase Gene

To investigate the role of gangliosides in the pathogenesis of prion diseases, intracerebral transmission study was performed using KO mice lacking GD2/GM2 synthase (GD2/ GM2 KO), GD3 synthase (GD3 KO), or GM3 synthase (GM3 $\mathrm{KO})$. These $\mathrm{KO}$ mice lack particular ganglioside species, depending on the ablated ganglioside synthase gene (Figure 1). For a mouse-adapted scrapie strain Chandler, the mean incubation time of GD2/GM2 KO mice $(126.6 \pm 0.3$ days) was reduced by $20 \%$ compared with that of WT mice $(157.5 \pm 1.2$ days; $P<0.01)$ (Figure 2). The mean incubation time of GM3 KO mice was also slightly reduced (149.5 \pm 2.2 days; $P<0.01$ ). For a mouse-adapted Gerstmann-SträusslerScheinker syndrome strain Fukuoka-1, the mean incubation time of GD2/GM2 KO mice and GM3 KO mice was reduced compared with that of WT mice, although the differences were not statistically significant.

\section{Neuropathology}

Prion strains are characterized by neuropathological features and biochemical properties of $\operatorname{PrP}^{\mathrm{Sc}}$ in the inoculated mice. Therefore, neuropathological analysis of the inoculated mice was performed to examine whether the strain characteristics were altered by the ablation of the ganglioside synthase gene. In the Chandler-inoculated mice, spongiform changes were distributed through the cerebral and cerebellar cortices, striatum, thalamus, hippocampus, pons, and cerebellar white matter (Figure $3 \mathrm{~A}$ ). In the Fukuoka-1-inoculated mice, the vacuoles of spongiform changes became larger and were distributed more intensively in the pons and cerebellar white matter (Figure 3, B and $\mathrm{C}$ ). There was no difference in the distribution of spongiform changes among mouse strains (Figure 3C). However, in immunohistochemical analysis of diseaseassociated $\operatorname{PrP}, \operatorname{PrP}^{\mathrm{TSE}}, \mathrm{GD} 2 / \mathrm{GM} 2 \mathrm{KO}$ mice inoculated with the Chandler strain showed decreased $\operatorname{PrP}^{\mathrm{TSE}}$ deposition (Figure 3, A and D). In addition, Iba 1-positive microglia and GFAP-positive astroglia were also fewer in the Chandler-inoculated GD2/GM2 KO mice. For the Fukuoka-1 strain, GD2/GM2 KO mice showed decreased

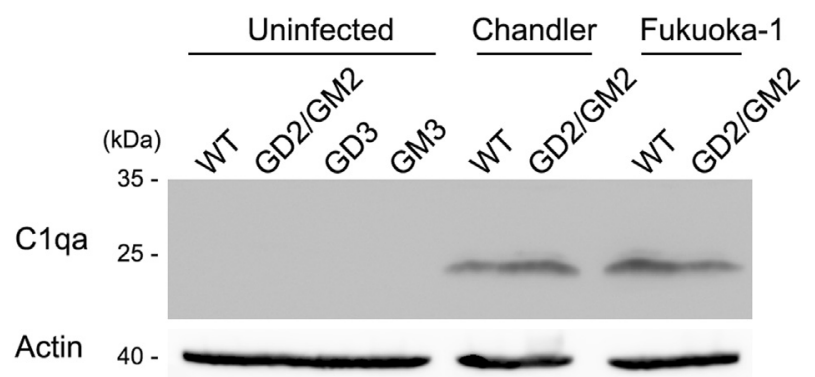

Figure 5 Activation of complement systems. Western blot analysis of C1qa in the brain of uninfected mice and Chandler- or Fukuoka1-inoculated mice. C1qa accumulated only in the prion-infected animals regardless of the mouse genotype or prion strain. A brain sample, equivalent to $1 \mathrm{mg}$ in wet weight, was loaded in each lane. WT, wild type. 
A

WT

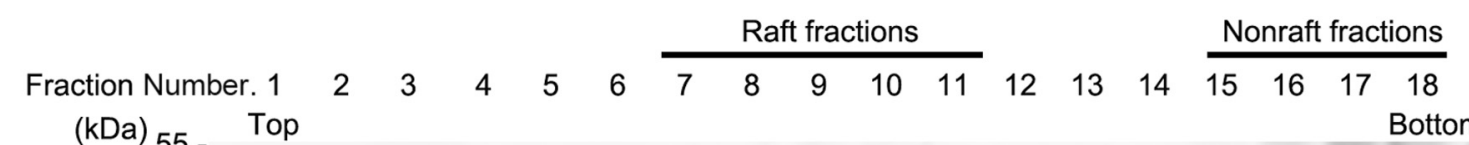

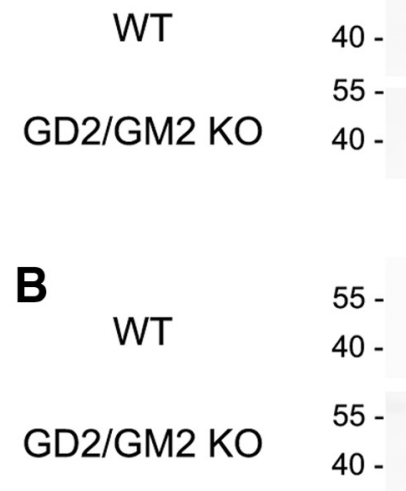

C

WT

35 -

25 -

Flotillin 1

\section{CD55 \\ CD55}

Bottom

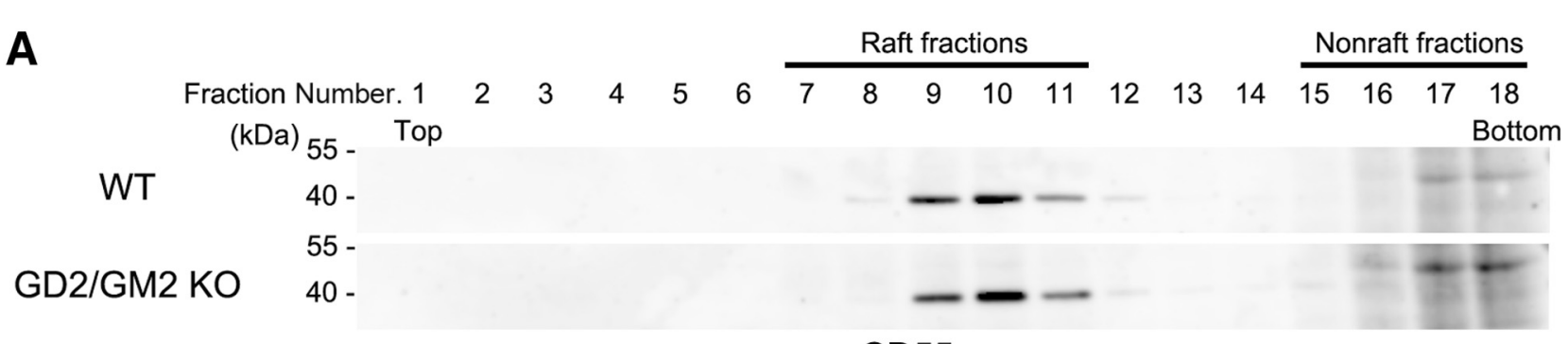

$0-$

55 -

는

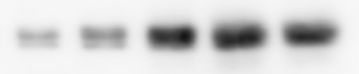

GD2/GM2 KO

$35-$

$25-$

D

WT $170-$

GD2/GM2 KO 170 -

PrP
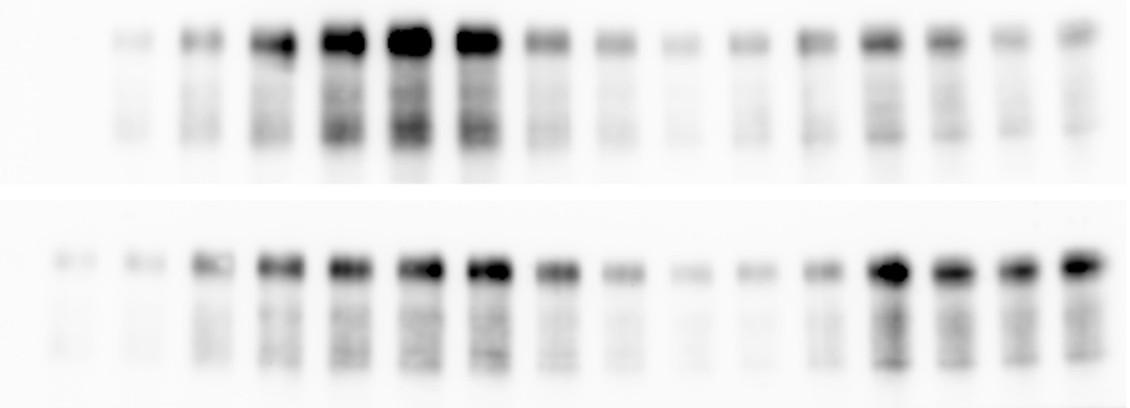

(1) 
decreased $\mathrm{PrP}^{\mathrm{Sc}}$ accumulation compared with WT, GD3 KO, or GM3 KO mice (Figure 4, A and B). The apparent amount of $\mathrm{PrP}^{\mathrm{Sc}}$ in Western blot analysis did not reflect the degree of $\operatorname{PrP}^{\mathrm{TSE}}$ deposition in the immunohistochemical analysis. For example, a GD2/GM2 KO mouse (number 145) that showed reduced $\operatorname{PrP}^{\mathrm{TSE}}$ deposition in the immunohistochemical analysis (ie, score 1) had similar apparent amount of $\mathrm{PrP}^{\mathrm{Sc}}$ to that of another GD2/GM2 KO mouse (number 203) that showed abundant $\operatorname{PrP}^{\mathrm{TSE}}$ deposition in the immunohistochemistry (ie, score 3) (Figure 4A). Thus, GD2/GM2 KO showed shortened incubation time, reduced $\mathrm{PrP}^{\mathrm{TSE}}$ deposition with attenuated glial reactions in neuropathological analysis, and slightly decreased PK-resistant $\mathrm{PrP}^{\mathrm{Sc}}$ accumulation in Western blot analysis.

In addition, the amount of $\operatorname{PrP}^{\mathrm{C}}$ was compared in the brain of uninfected KO mice because the expression level of $\operatorname{PrP}^{\mathrm{C}}$ can directly affect the incubation period. However, the amount of $\operatorname{PrP}^{\mathrm{C}}$ was not modified by the absence of ganglioside synthase genes (Figure 4C), suggesting that the expression level of $\mathrm{PrP}^{\mathrm{C}}$ is unrelated to the changes in incubation period.

\section{Evaluation of Complement System}

To gain insights into the shortened incubation period in GD2/GM2 KO mice, the involvement of complement system was examined because it has been reported that $\mathrm{KO}$ mice lacking both GD2/GM2 synthase and GD3 synthase show dispersion of GPI-anchored complement-regulatory proteins from lipid rafts and activation of the complement system. $^{12,13}$ To assess the activation of the complement system, the amount of a complement factor C1qa in the brain was compared between GD2/GM2 KO mice and WT mice by Western blot analysis (Figure 5). However, there was no difference in C1qa level between GD2/GM2 KO mice and WT mice. C1qa accumulated only in the prioninfected animals regardless of the mouse genotype or prion strain. In addition, although dispersion of GPIanchored complement-regulatory protein CD55 from lipid rafts has been demonstrated in KO mice lacking both GD2/ GM2 synthase and GD3 synthase, the floating patterns of CD55 were not different between GD2/GM2 KO mice and WT mice in the flotation assay of lipid raft-associated proteins in the brain (Figure 6A), suggesting that CD55 did not disperse from lipid rafts in GD2/GM2 KO mice. Thus, the shortened incubation period in the Chandlerinoculated GD2/GM2 $\mathrm{KO}$ mice was not due to altered activation of the complement system.

\section{Flotation Assay of PrPC and Lipid Raft-Associated Proteins}

It was subsequently investigated whether $\operatorname{PrP}^{\mathrm{C}}$ and lipid raft-associated proteins other than CD55 disperse from lipid rafts in GD2/GM2 KO mice by flotation assay. As reported previously, ${ }^{13}$ a lipid raft marker, flotillin 1, dispersed from the lipid raft fractions (fractions 7 to 11) to the nonraft fractions (fractions 15 to 18 ) in GD2/GM2 KO mice (Figure 6B). Furthermore, $\operatorname{PrP}^{\mathrm{C}}$ also dispersed from the lipid raft fractions to the nonraft fractions in GD2/GM2 KO mice (Figure 6C). In contrast, the floating patterns of a GPI-anchored PrP-associated calcium channel protein CACNA2D $1^{29,30}$ or those of a GPI-anchored protein Thy 1 were not different between GD2/GM2 KO mice and WT mice (Figure 6, D and E). Thus, certain lipid raft-associated proteins, including $\operatorname{PrP}^{\mathrm{C}}$, dispersed from lipid rafts in the brain of GD2/GM2 $\mathrm{KO}$ mice.

\section{Discussion}

Herein, we found that GD2/GM2 KO mice inoculated with the Chandler prion strain showed shortened incubation time, reduced $\operatorname{PrP}^{\mathrm{TSE}}$ deposition with attenuated glial reactions in neuropathological analysis, slightly decreased PK-resistant $\mathrm{PrP}^{\mathrm{Sc}}$ accumulation in Western blot analysis, and reduced localization of PrP to lipid rafts.

The reduced localization of PrP to lipid rafts might affect the formation of $\mathrm{PrP}^{\mathrm{Sc}}$ in GD2/GM2 KO mice. Although the localization of $\mathrm{PrP}^{\mathrm{Sc}}$ to lipid rafts could not be examined, dispersion of lipid raft-associated proteins, including $\mathrm{PrP}^{\mathrm{C}}$ from lipid rafts, was confirmed in GD2/GM2 $\mathrm{KO}$ mice in the present study. Because the localization to lipid rafts is important for the conformational conversion of $\mathrm{PrP}^{\mathrm{C}}$ into $\mathrm{PrP}^{\mathrm{Sc}}{ }^{3}$ the dispersion of $\mathrm{PrP}^{\mathrm{C}}$ and/or $\operatorname{PrP}^{\mathrm{Sc}}$ from lipid rafts might result in the decreased accumulation of $\mathrm{PrP}^{\mathrm{TSE}}$ and PK-resistant $\mathrm{PrP}^{\mathrm{Sc}}$ in the Chandler-inoculated GD2/GM2 $\mathrm{KO}$ mice. The amount of PK-resistant $\mathrm{PrP}^{\mathrm{Sc}}$ in the Chandler-inoculated GD2/GM2 KO mice in the Western blot analysis did not reflect the marked reduction of $\mathrm{PrP}^{\mathrm{TSE}}$ deposition in the immunohistochemical analysis compared with the other mouse strains. In addition, even in the Chandler-inoculated GD2/GM2 KO mouse group, the apparent amount of PK-resistant $\mathrm{PrP}^{\mathrm{Sc}}$ did not reflect the $\operatorname{PrP}^{\mathrm{TSE}}$ deposition score in the immunohistochemical analysis. This finding raises a possibility that the amount of PK-sensitive $\mathrm{PrP}^{\mathrm{Sc} 31-33}$ might largely decrease in the Chandler-inoculated GD2/GM2 KO mice. Meanwhile, the incubation time was shortened in the Chandler-inoculated GD2/GM2 KO mice despite the decreased $\mathrm{PrP}^{\mathrm{Sc}}$ accumulation. To account for this discrepancy, further studies will be needed in the future addressing the questions of whether the dispersion of $\operatorname{PrP}^{\mathrm{Sc}}$ and/or $\operatorname{PrP}^{\mathrm{C}}$ from lipid rafts reduces the formation of $\mathrm{PK}$-sensitive $\mathrm{PrP}^{\mathrm{Sc}}$ or affects the neurotoxicity of $\mathrm{PrP}^{\mathrm{Sc}}$.

There remains a possibility that the alteration in ganglioside composition might directly affect the conformation of PrP. The ablation of ganglioside synthase causes massive alteration of ganglioside composition. ${ }^{17}$ For example, an ablation of GD2/GM2 synthase causes depletion of GD2, GM2, and downstream gangliosides, such as GM1, and results in accumulation of GD3 and GM3 ${ }^{16,34} \mathrm{PrP}^{\mathrm{C}}$ is 
colocalized and coimmunoprecipitated with GM1 and GM3 ${ }^{35,36}$ GM1 binds to the C-terminus of PrP and modifies the conformational properties of $\operatorname{PrP} .^{37,38}$ Similarly, GM1 binds to amyloid $\beta$ and modifies the conformation of amyloid $\beta$, resulting in the formation of endogenous seeds for amyloid fibril formation. ${ }^{39}$ Therefore, the direct effects of gangliosides on PrP conformation are not negligible. To test this hypothesis, analysis of conformational properties of $\mathrm{PrP}^{\mathrm{C}}$ and $\mathrm{PrP}^{\mathrm{Sc}}$ from GD2/GM2 KO mice will be needed in the future.

A possibility that the alteration in ganglioside composition might affect the activation of glial cells cannot be excluded. Although the role of glial cells in the pathogenesis of prion diseases is controversial, both microglia and astroglia are activated in prion diseases. ${ }^{40-43}$ The decreased number of microglia and astroglia in the Chandlerinoculated GD2/GM2 KO mice might simply reflect the decreased $\operatorname{PrP}^{\mathrm{TSE}}$ deposition. However, although the amount of $\operatorname{PrP}^{\mathrm{TSE}}$ deposition was not altered, the Fukuoka1-inoculated GD2/GM2 KO mice also showed attenuated microglial reaction. Therefore, the altered ganglioside composition may affect glial reactions regardless of the $\operatorname{PrP}^{\mathrm{TSE}}$ accumulation. Indeed, ethanol-induced astroglial activation is attenuated in GD2/GM2 KO mice. ${ }^{44}$ Further studies will be required to examine whether the shortened incubation time in GD2/GM2 $\mathrm{KO}$ mice relates to the attenuated microglial reaction, including neuroprotective microglia. ${ }^{45,46}$

In conclusion, we have shown that the ablation of GD2/ GM2 synthase gene causes a significant reduction in incubation time of prion infection. The present study suggests that the gangliosides may have an important role in prion disease pathogenesis by affecting the localization of PrP to lipid rafts.

\section{Acknowledgments}

We thank Drs. Motohiro Horiuchi and Takeshi Yamasaki (Faculty of Veterinary Medicine, Hokkaido University) for providing the prion inoculum and technical assistance.

\section{Supplemental Data}

Supplemental material for this article can be found at https://doi.org/10.1016/j.ajpath.2018.11.009.

\section{References}

1. Prusiner SB, Scott MR, DeArmond SJ, Cohen FE: Prion protein biology. Cell 1998, 93:337-348

2. Harmey JH, Doyle D, Brown V, Rogers MS: The cellular isoform of the prion protein, $\mathrm{PrPc}$, is associated with caveolae in mouse neuroblastoma (N2a) cells. Biochem Biophys Res Commun 1995, 210: $753-759$

3. Taraboulos A, Scott M, Semenov A, Avrahami D, Laszlo L, Prusiner SB: Cholesterol depletion and modification of $\mathrm{COOH}-$ terminal targeting sequence of the prion protein inhibit formation of the scrapie isoform. J Cell Biol 1995, 129:121-132

4. Vey M, Pilkuhn S, Wille H, Nixon R, DeArmond SJ, Smart EJ, Anderson RG, Taraboulos A, Prusiner SB: Subcellular colocalization of the cellular and scrapie prion proteins in caveolae-like membranous domains. Proc Natl Acad Sci U S A 1996, 93:14945-14949

5. Naslavsky N, Stein R, Yanai A, Friedlander G, Taraboulos A: Characterization of detergent-insoluble complexes containing the cellular prion protein and its scrapie isoform. J Biol Chem 1997, 272: 6324-6331

6. Naslavsky N, Shmeeda H, Friedlander G, Yanai A, Futerman AH, Barenholz Y, Taraboulos A: Sphingolipid depletion increases formation of the scrapie prion protein in neuroblastoma cells infected with prions. J Biol Chem 1999, 274:20763-20771

7. Brown DA, Rose JK: Sorting of GPI-anchored proteins to glycolipidenriched membrane subdomains during transport to the apical cell surface. Cell 1992, 68:533-544

8. Simons K, Ikonen E: Functional rafts in cell membranes. Nature 1997 , 387:569-572

9. Bollinger CR, Teichgräber V, Gulbins E: Ceramide-enriched membrane domains. Biochim Biophys Acta 2005, 1746:284-294

10. Groux-Degroote S, Guérardel Y, Delannoy P: Gangliosides: structures, biosynthesis, analysis, and roles in cancer. Chembiochem 2017, 18: $1146-1154$

11. Kabayama K, Sato T, Kitamura F, Uemura S, Kang BW, Igarashi Y, Inokuchi J: TNFalpha-induced insulin resistance in adipocytes as a membrane microdomain disorder: involvement of ganglioside GM3. Glycobiology 2005, 15:21-29

12. Ohmi Y, Tajima O, Ohkawa Y, Mori A, Sugiura Y, Furukawa K, Furukawa K: Gangliosides play pivotal roles in the regulation of complement systems and in the maintenance of integrity in nerve tissues. Proc Natl Acad Sci U S A 2009, 106:22405-22410

13. Ohmi Y, Tajima O, Ohkawa Y, Yamauchi Y, Sugiura Y, Furukawa K, Furukawa K: Gangliosides are essential in the protection of inflammation and neurodegeneration via maintenance of lipid rafts: elucidation by a series of ganglioside-deficient mutant mice. J Neurochem 2011, 116:926-935

14. Kovacs GG, Gasque P, Ströbel T, Lindeck-Pozza E, Strohschneider M, Ironside JW, Budka H, Guentchev M: Complement activation in human prion disease. Neurobiol Dis 2004, 15:21-28

15. Hasebe R, Raymond GJ, Horiuchi M, Caughey B: Reaction of complement factors varies with prion strains in vitro and in vivo. Virology 2012, 423:205-213

16. Liu Y, Wada R, Kawai H, Sango K, Deng C, Tai T, McDonald MP, Araujo K, Crawley JN, Bierfreund U, Sandhoff K, Suzuki K, Proia RL: A genetic model of substrate deprivation therapy for a glycosphingolipid storage disorder. J Clin Invest 1999, 103:497-505

17. Yamashita T, Hashiramoto A, Haluzik M, Mizukami H, Beck S, Norton A, Kono M, Tsuji S, Daniotti JL, Werth N, Sandhoff R, Sandhoff K, Proia RL: Enhanced insulin sensitivity in mice lacking ganglioside GM3. Proc Natl Acad Sci U S A 2003, 100:3445-3449

18. Chandler RL: Encephalopathy in mice produced by inoculation with scrapie brain material. Lancet 1961, 1:1378-1379

19. Tateishi J, Ohta M, Koga M, Sato Y, Kuroiwa Y: Transmission of chronic spongiform encephalopathy with kuru plaques from humans to small rodents. Ann Neurol 1979, 5:581-584

20. Kitamoto T, Mohri S, Ironside JW, Miyoshi I, Tanaka T, Kitamoto N, Itohara S, Kasai N, Katsuki M, Higuchi J, Muramoto T, Shin RW: Follicular dendritic cell of the knock-in mouse provides a new bioassay for human prions. Biochem Biophys Res Commun 2002, 294: $280-286$

21. Kitamoto T, Shin RW, Doh-ura K, Tomokane N, Miyazono M, Muramoto T, Tateishi J: Abnormal isoform of prion proteins accumulates in the synaptic structures of the central nervous system in patients with Creutzfeldt-Jakob disease. Am J Pathol 1992, 140:1285-1294

22. Kitamoto T, Muramoto T, Hilbich C, Beyreuther K, Tateishi J: Nterminal sequence of prion protein is also integrated into kuru plaques 
in patients with Gerstmann-Sträussler syndrome. Brain Res 1991, 545: 319-321

23. Munesue Y, Shimazaki T, Qi Z, Isoda N, Sawa H, Aoshima K, Kimura T, Mohri S, Kitamoto T, Kobayashi A: Development of a quick bioassay for the evaluation of transmission properties of acquired prion diseases. Neurosci Lett 2018, 668:43-47

24. Grathwohl KU, Horiuchi M, Ishiguro N, Shinagawa M: Improvement of $\mathrm{PrP}^{\mathrm{Sc}}$-detection in mouse spleen early at the preclinical stage of scrapie with collagenase-completed tissue homogenization and Sarkosyl-NaCl extraction of PrP ${ }^{\mathrm{Sc}}$. Arch Virol 1996, 141:1863-1874

25. Hizume M, Kobayashi A, Teruya K, Ohashi H, Ironside JW, Mohri S, Kitamoto T: Human prion protein (PrP) $219 \mathrm{~K}$ is converted to $\operatorname{PrP}^{\mathrm{Sc}}$ but shows heterozygous inhibition in variant Creutzfeldt-Jakob disease infection. J Biol Chem 2009, 284:3603-3609

26. Baron GS, Hughson AG, Raymond GJ, Offerdahl DK, Barton KA, Raymond LD, Dorward DW, Caughey B: Effect of glycans and the glycophosphatidylinositol anchor on strain dependent conformations of scrapie prion protein: improved purifications and infrared spectra. Biochemistry 2011, 50:4479-4490

27. Asano M, Mohri S, Ironside JW, Ito M, Tamaoki N, Kitamoto T: vCJD prion acquires altered virulence through trans-species infection. Biochem Biophys Res Commun 2006, 342:293-299

28. Kanda Y: Investigation of the freely available easy-to-use software "EZR" for medical statistics. Bone Marrow Transplant 2013, 48: $452-458$

29. Senatore A, Colleoni S, Verderio C, Restelli E, Morini R, Condliffe SB, Bertani I, Mantovani S, Canovi M, Micotti E, Forloni G, Dolphin AC, Matteoli M, Gobbi M, Chiesa R: Mutant PrP suppresses glutamatergic neurotransmission in cerebellar granule neurons by impairing membrane delivery of VGCC $\alpha(2) \delta-1$ subunit. Neuron 2012, $74: 300-313$

30. Alvarez-Laviada A, Kadurin I, Senatore A, Chiesa R, Dolphin AC: The inhibition of functional expression of calcium channels by prion protein demonstrates competition with $\alpha 2 \delta$ for GPI-anchoring pathways. Biochem J 2014, 458:365-374

31. Safar J, Wille H, Itri V, Groth D, Serban H, Torchia M, Cohen FE, Prusiner SB: Eight prion strains have $\mathrm{PrP}(\mathrm{Sc})$ molecules with different conformations. Nat Med 1998, 4:1157-1165

32. Tzaban S, Friedlander G, Schonberger O, Horonchik L, Yedidia Y, Shaked G, Gabizon R, Taraboulos A: Protease-sensitive scrapie prion protein in aggregates of heterogeneous sizes. Biochemistry 2002, 41: $12868-12875$

33. Safar JG, Geschwind MD, Deering C, Didorenko S, Sattavat M, Sanchez H, Serban A, Vey M, Baron H, Giles K, Miller BL, Dearmond SJ, Prusiner SB: Diagnosis of human prion disease. Proc Natl Acad Sci U S A 2005, 102:3501-3506
34. Takamiya K, Yamamoto A, Furukawa K, Yamashiro S, Shin M, Okada M, Fukumoto S, Haraguchi M, Takeda N, Fujimura K, Sakae M, Kishikawa M, Shiku H, Furukawa K, Aizawa S: Mice with disrupted GM2/GD2 synthase gene lack complex gangliosides but exhibit only subtle defects in their nervous system. Proc Natl Acad Sci U S A 1996, 93:10662-10667

35. Mattei V, Garofalo T, Misasi R, Gizzi C, Mascellino MT, Dolo V, Pontieri GM, Sorice M, Pavan A: Association of cellular prion protein with gangliosides in plasma membrane microdomains of neural and lymphocytic cells. Neurochem Res 2002, 27:743-749

36. Mattei V, Garofalo T, Misasi R, Circella A, Manganelli V, Lucania G, Pavan A: Sorice M: Prion protein is a component of the multimolecular signaling complex involved in T cell activation. FEBS Lett 2004, 560: $14-18$

37. Sanghera N, Correia BE, Correia JR, Ludwig C, Agarwal S, Nakamura HK, Kuwata K, Samain E, Gill AC, Bonev BB, Pinheiro TJ: Deciphering the molecular details for the binding of the prion protein to main ganglioside GM1 of neuronal membranes. Chem Biol 2011, $18: 1422-1431$

38. Botto L, Cunati D, Coco S, Sesana S, Bulbarelli A, Biasini E, Colombo L, Negro A, Chiesa R, Masserini M, Palestini P: Role of lipid rafts and GM1 in the segregation and processing of prion protein. PLoS One 2014, 9:e98344

39. Yanagisawa K: GM1 ganglioside and Alzheimer's disease. Glycoconj J 2015, 32:87-91

40. Miyazono M, Iwaki T, Kitamoto T, Kaneko Y, Doh-ura K, Tateishi J: A comparative immunohistochemical study of Kuru and senile plaques with a special reference to glial reactions at various stages of amyloid plaque formation. Am J Pathol 1991, 139:589-598

41. Williams A, Lucassen PJ, Ritchie D, Bruce M: PrP deposition, microglial activation, and neuronal apoptosis in murine scrapie. Exp Neurol 1997, 144:433-438

42. Aguzzi A, Liu Y: A role for astroglia in prion diseases. J Exp Med 2017, 214:3477-3479

43. Aguzzi A, Zhu C: Microglia in prion diseases. J Clin Invest 2017, 127 3230-3239

44. Saito M, Wu G, Hui M, Masiello K, Dobrenis K, Ledeen RW, Saito M: Ganglioside accumulation in activated glia in the developing brain: comparison between WT and GalNAcT KO mice. J Lipid Res 2015, $56: 1434-1448$

45. Zhu C, Herrmann US, Falsig J, Abakumova I, Nuvolone M, Schwarz P, Frauenknecht K, Rushing EJ, Aguzzi A: A neuroprotective role for microglia in prion diseases. J Exp Med 2016, 213:1047-1059

46. Carroll JA, Race B, Williams K, Striebel J, Chesebro B: Microglia are critical in host defense against prion disease. J Virol 2018, [Epub ahead of print] doi:10.1128/JVI.00549-18 